УДК 622.276

\title{
СОВЕРШЕНСТВОВАНИЕ КИСЛОТНЫХ ОБРАБОТОК В КОЛЛЕКТОРАХ, ХАРАКТЕРИЗУЮЩИХСЯ РАЗЛИЧНОЙ КАРБОНАТНОСТЬЮ (НА ПРИМЕРЕ НЕФТЯНЫХ МЕСТОРОЖДЕНИЙ ПЕРМСКОГО КРАЯ)
}

\author{
Мартюшев Дмитрий Александрович ${ }^{1}$, \\ martyushevd@inbox.ru \\ Новиков Владимир Андреевич², \\ novikov.vladimir.andr@gmail.com \\ 1 Пермский национальный исследовательский политехнический университет, \\ Россия, 614990, г. Пермь, пр. Комсомольский, 29. \\ 2 Филиал ООО «ЛУКОЙЛ-Инжиниринг» «ПермНИПИнефть» в г. Перми, \\ Россия, 614000, г. Пермь, ул. Советской Армии, 29.
}

\begin{abstract}
Актуальность работы обусловлена тем, что технологические параметры проведения кислотной обработки (время выдержки в пласте и объем состава) значительно влияют на результат геолого-технического мероприятия. По мнению многих специалистов, требует изучения вопрос о необходимости в технологическом процессе проведения обработки этапа выдержки кислоты в пласте и его продолжительности. Удельный объем кислотного состава, или его количество в расчете на метр обрабатываемой толщины пласта, определяется различными факторами, такими как состав горной породы, свойства призабойной зоны, желаемая глубина проникновения состава в пласт и др.

Цель: оценка влияния технологических параметров проведения кислотных обработок на эффеективность мероприятия на нефртяных месторождениях Пермского края, характеризующихся различной карбонатностью горных пород.

Методом исследования является проведение лабораторных экспериментов с использованием прибора для определения карбонатности горных пород - карбонатомера КМ-04М, фильтрационных установок с моделированием пластовых условий УИК5ВГ и AFS-300, а также установки микрофокусной рентгеноскопии.

Результаты. На образцах керна месторождений Пермского края, отличающихся содержанием компонентов «кальцитдоломит-нерастворимый остаток» проведено моделирование кислотного воздействия с использованием двух кислотных составов с определением коэфффициента изменения проницаемости и рентгенотомографическими исследованиями. Рентгенотомографические эксперименты на одном образце керна выполнены дважды: до и после моделирования кислотного воздействия. По данным фильтрационных и рентгенотомографических экспериментов подобраны условия эфффективного применения кислотных составов на рассматриваемых месторождениях. Обобщение всех результатов позволило разработать рекомендации по оптимизации технологических параметров проведения обработок на рассматриваемых объектах. Применение рентгеновской томографрии позволило выделить случаи, для которых в результате воздействия характерен прирост пустотности, но снижение проницаемости. Данный факт позволит проводить дальнейшие работы по совершенствованию рецептур составов и технологий их применения.
\end{abstract}

Ключевые слова:

Кислотные обработки, карбонатные коллектора, фильтрационные исследования, томографические исследования, коэфффициент восстановления проницаемости, технологические параметры, время выдержки в пласте, объем закачиваемого состава, технологическая эффеективность.

\section{Введение}

Одним из наиболее распространенных методов повышения продуктивности скважин на месторождениях Пермского края является проведение солянокислотных обработок различных видов. Данный метод является наиболее простым и имеет большой опыт применения как на месторождениях Пермского края, так и за его пределами. Несмотря на это, стоит серьезно относиться к планированию кислотного воздействия, так как по статистике около 45 \% проведенных операций не достигают ожидаемого эффекта [1-7].

При проведении кислотных обработок значительное влияние на результат мероприятия оказывают технологические параметры, к которым относят:

- наличие этапа выдержки кислотного состава в пласте на реакцию и его продолжительность;

- расход кислотного состава на метр обрабатываемой толщины пласта;
- скорость закачки кислотного состава в пласт.

Необходимость в технологическом процессе проведения обработки этапа выдержки кислоты в пласте и времени его продолжительности, по мнению многих специалистов, требует изучения.

По данным [8] известны две технологические схемы проведения обработок. Первая заключается в продавке кислотного состава технологической жидкостью в объеме, равном объему насосно-компрессорных труб (НКТ), и выдерживании в пласте на реакции до нейтрализации кислоты. По второй схеме, предложенной В.М. Березиным, объем продавочной жидкости увеличивается на величину объема растворенной породы и скважина осваивается без выдерживания кислоты на реакции.

Так, в [9] приводится информация о том, что при обработке карбонатных коллекторов выдержка кислоты нежелательна, так как в пластовых условиях она нейтрализуется еще на этапе прохождения по поровым каналам и трещинам, а своевременное удаление 
состава после реакции позволит предотвратить закупорку пустотного пространства.

Удельный объем кислотного состава, или его количество в расчете на метр обрабатываемой толщины пласта, определяется различными факторами, такими как свойства призабойной зоны, желаемая глубина проникновения состава в пласт и др.

На практике объемы закачиваемых кислотных составов обычно определяют эмпирическим путем [9]. При первичной кислотной обработке, направленной на растворение пород и примесей, обычно закачивают $0,5 \mathrm{~m} / \mathrm{m}$ кислотного состава. При повторной обработке расход принято увеличивать вдвое.

В работе [10] автор приводит выводы о том, что увеличение удельного расхода кислотного состава является одним из путей повышения технологической эффективности кислотных обработок.

Таким образом, подбор технологических параметров (объем состава, время выдержки, скорость закачки) проведения кислотного воздействия на карбонатные коллектора должен проводиться с учетом строения и петрофизических свойств горных пород.
Для определения оптимальных технологических параметров проведения кислотной обработки различными составами авторами проведена серия фильтрационных испытаний на современном оборудовании при термодинамических условиях, соответствующих пластовым, для рассматриваемых объектов [11-17]. К исследованию приняты два кислотных состава (Состав 1 и Состав 2 - реальные названия составов не указаны в связи с конфиденциальностью данной информации), которые наиболее распространены на территории Пермского края и применяются в настоящее время. Основные свойства кислотных составов приведены в табл. 1.

Для моделирования кислотного воздействия на образцах керна с различными технологическими параметрами нами были выбраны семь карбонатных объектов (одного геологического возраста) месторождений Пермского края, характеризующиеся значительными остаточными извлекаемыми запасами и отличающиеся между собой карбонатностью горных пород. Основные геолого-физические характеристики рассматриваемых объектов представлены в табл. 2.

Таблица 1. Основные свойства кислотных композиций

Table 1. Basic properties of acid compositions

\begin{tabular}{|c|c|c|}
\hline $\begin{array}{l}\text { Показатель } \\
\text { Indicator }\end{array}$ & $\begin{array}{c}\text { Состав } 1 \\
\text { Composition } 1\end{array}$ & $\begin{array}{c}\text { Состав } 2 \\
\text { Composition } 2\end{array}$ \\
\hline $\begin{array}{l}\text { Внешний вид } \\
\text { Appearance }\end{array}$ & $\begin{array}{c}\text { Прозрачная жидкость от бесцветной } \\
\text { до темно-коричневого цвета } \\
\text { Clear liquid from colorless to dark brown }\end{array}$ & $\begin{array}{c}\text { Прозрачная жидкость от бесцветной } \\
\text { до коричневого цвета } \\
\text { Clear liquid from colorless to brown color }\end{array}$ \\
\hline $\begin{array}{l}\text { Массовая доля соляной кислоты, \% в пределах } \\
\text { Mass fraction of hydrochloric acid, \% within }\end{array}$ & $10,5-14,5$ & $10,5-14,5$ \\
\hline $\begin{array}{l}\text { Плотность при } 20^{\circ} \mathrm{C}, \Gamma / \mathrm{cm}^{3} \text {, в пределах } \\
\text { Density at } 20^{\circ} \mathrm{C}, \mathrm{g} / \mathrm{cm}^{3} \text {, within }\end{array}$ & $1,04-1,09$ & $1,04-1,08$ \\
\hline \multirow{4}{*}{$\begin{array}{l}\text { Компонентный состав } \\
\text { Component composition }\end{array}$} & \multicolumn{2}{|c|}{$\begin{array}{l}\text { Водный раствор соляной кислоты } \\
\text { Aqueous hydrochloric acid solution }\end{array}$} \\
\hline & $\begin{array}{l}\text { Ингибитор коррозии } \\
\text { Corrosion inhibitor }\end{array}$ & $\begin{array}{c}\text { Высокоэффективные целевые добавки } \\
\text { Highly effective target supplements }\end{array}$ \\
\hline & $\begin{array}{c}\text { ПAB } \\
\text { surfactants }\end{array}$ & $\begin{array}{c}\text { ПAB } \\
\text { surfactants }\end{array}$ \\
\hline & - & $\begin{array}{l}\text { Модифицирующие компоненты } \\
\text { Modifying components }\end{array}$ \\
\hline
\end{tabular}

Таблица 2. Геолого-физическая характеристика исследуемых объектов

Table 2. Geological and physical characteristics of the studied objects

\begin{tabular}{|c|c|c|c|c|c|c|c|}
\hline \multirow[b]{2}{*}{$\begin{array}{l}\text { Параметр } \\
\text { Indicator }\end{array}$} & \multicolumn{7}{|c|}{ Месторождение/Field } \\
\hline & $\begin{array}{c}\text { Гагаринское } \\
\text { Gagarinskoe }\end{array}$ & $\begin{array}{l}\text { Маговское } \\
\text { Magovskoe }\end{array}$ & $\begin{array}{c}\text { им. Сухарева } \\
\text { behalf of } \\
\text { Sukharev } \\
\end{array}$ & $\begin{array}{l}\text { Озерное } \\
\text { Ozernoe }\end{array}$ & $\begin{array}{l}\text { Баклановское } \\
\text { Baklanovskoe }\end{array}$ & $\begin{array}{l}\text { Винниковское } \\
\text { Vinnikovskoe }\end{array}$ & $\begin{array}{l}\text { Дороховское } \\
\text { Dorokhovskoe }\end{array}$ \\
\hline $\begin{array}{l}\text { Средняя глубина залегания, м } \\
\text { Average depth, m }\end{array}$ & 2001,0 & 2270,0 & 1950,0 & 1997,0 & 1300,0 & 1795,0 & 1959,0 \\
\hline $\begin{array}{l}\text { Пористость, \% } \\
\text { Porosity, \% }\end{array}$ & 11,0 & 10,0 & 11,0 & 9,0 & 15,0 & 10,0 & 11,0 \\
\hline $\begin{array}{l}\text { Проницаемость, мД } \\
\text { Permeability, md }\end{array}$ & 39,0 & 4,0 & 25,0 & 29,0 & 26,0 & 18,0 & 42,0 \\
\hline $\begin{array}{l}\text { Средняя эфф. нефтенас. } \\
\text { толщина, м } \\
\text { Average net pay thickness, m }\end{array}$ & 12,3 & 22,2 & 13,2 & 15,7 & 3,4 & 2,1 & 4,2 \\
\hline $\begin{array}{l}\text { Вязкость нефти в пл. усл., мПа*с } \\
\text { Oil viscosity at reservoir } \\
\text { conditions, } \mathrm{MPa} * \mathrm{c}\end{array}$ & 1,13 & 0,97 & 1,5 & 1,31 & 7,8 & 6,8 & 1,98 \\
\hline $\begin{array}{l}\text { Газосодержание, } \text { м }^{3} / \mathrm{T} \\
\text { Gas content, } \mathrm{m}^{3} / \mathrm{t}\end{array}$ & 185,6 & 291,6 & 125,0 & 141,0 & 30,3 & 43,5 & 76,0 \\
\hline \begin{tabular}{|l|} 
Рпл начальное, $\mathrm{MПа}$ \\
Initial reservoir pressure, $\mathrm{MPa}$
\end{tabular} & 20,7 & 23,0 & 21,5 & 18,2 & 12,6 & 17,8 & 17,8 \\
\hline $\begin{array}{l}\text { Давление насыщения, МПа } \\
\text { Saturation pressure, MPa }\end{array}$ & 14,4 & 16,2 & 12,0 & 11,0 & 9,4 & 7,2 & 10,7 \\
\hline
\end{tabular}




\section{Оценка карбонатности горных пород}

и проведение исследований в свободном объеме

Карбонатность, характеризующая содержание в горной породе кальцита, доломита и других компонентов, является важнейшей характеристикой, определяющей успешность того или иного химического воздействия. С целью оценки карбонатности образцов горных пород выполнены специальные исследования с применением прибора - карбонатомера. Карбонатность горных пород рассматриваемых месторождений Пермского края представлена в табл. 3.

Таблица 3. Результаты определения карбонатности горных пород

Table 3. Results of determination of carbonate rocks

\begin{tabular}{|c|c|c|c|c|}
\hline \multirow{2}{*}{$\begin{array}{c}\text { Месторождение } \\
\text { Field }\end{array}$} & $\begin{array}{c}\text { Количество исследований } \\
\text { Number of studies }\end{array}$ & $\begin{array}{c}\text { Кальцит } \\
\text { Calcite }\end{array}$ & $\begin{array}{c}\text { Доломит } \\
\text { Dolomite }\end{array}$ & $\begin{array}{c}\text { Нерастворимый остаток* } \\
\text { Insoluble residue }\end{array}$ \\
\hline $\begin{array}{c}\text { Гагаринское } \\
\text { Gagarinskoe }\end{array}$ & 18 & $\frac{85,3-87,6^{* *}}{86,5}$ & $\frac{8,6-9,7}{9,2}$ & $\frac{3,8-5,0}{4,3}$ \\
\hline $\begin{array}{c}\text { Maroвское } \\
\text { Magovskoe }\end{array}$ & 15 & $\frac{85,9-88,6}{87,1}$ & $\frac{1,2-1,3}{1,3}$ & $\frac{10,1-12,9}{11,6}$ \\
\hline $\begin{array}{c}\text { им. Cyхарева } \\
\text { behalf of Sukharev }\end{array}$ & 15 & $\frac{54,2-59,6}{57,5}$ & $\frac{28,1-30,1}{29,3}$ & $\frac{11,2-16,1}{13,2}$ \\
\hline $\begin{array}{c}\text { Oзерное } \\
\text { Ozernoe }\end{array}$ & 18 & $\frac{9,2-12,7}{10,8}$ & $\frac{75,6-78,2}{77,1}$ & $\frac{11,7-12,6}{12,1}$ \\
\hline $\begin{array}{c}\text { Баклановское } \\
\text { Ваklanovskoe }\end{array}$ & 22 & $\frac{55,0-58,9}{57,3}$ & $\frac{2,3-2,9}{2,7}$ & $\frac{38,8-42,1}{40,0}$ \\
\hline $\begin{array}{c}\text { Винниковское } \\
\text { Vinnikovsky }\end{array}$ & 12 & $\frac{82,5-87,3}{84,6}$ & $\frac{12,7-17,5}{15,4}$ \\
\hline $\begin{array}{c}\text { Дороховское } \\
\text { Dorokhovskoe }\end{array}$ & 20 & $\frac{95,5-97,3}{96,2}$ & $\frac{0-0,7}{0,3}$ & $\frac{2,7-4,3}{3,5}$ \\
\hline
\end{tabular}

Примечание: " нерастворимый остаток в основном представлен аргиллитами и алевролитовой квариевой примесью; ** интервал изменения компонента/среднее значение.

Note: ${ }^{*}$ the insoluble residue is mainly represented by mudstones and siltstone quartz impurities; ${ }^{* *}$ the range of variation of component/average.

Важным параметром при расчете дизайна кислотного воздействия является время нейтрализации кислотного состава, который зависит от компонентов, входящих в состав горной породы [18-20]. Факт наличия или отсутствия реакции можно оценить как по выделению углекислого газа (визуально), так и регулярным измерением $\mathrm{pH}$ показателя с помощью прибора S47 Seven Multi (табл. 4).

Таблица 4. Оценка времени нейтрализации кислотных составов

Table 4. Time neutralize acidic formulations

\begin{tabular}{|l|c|c|}
\hline \multirow{2}{*}{$\begin{array}{c}\text { Месторождение } \\
\text { Field }\end{array}$} & \multicolumn{2}{|c|}{$\begin{array}{c}\text { Время нейтрализации, мин } \\
\text { Neutralization time, min }\end{array}$} \\
\cline { 2 - 3 } & $\begin{array}{c}\text { Состав 1 } \\
\text { Composition 1 }\end{array}$ & $\begin{array}{c}\text { Состав 2 } \\
\text { Composition 2 }\end{array}$ \\
\hline $\begin{array}{l}\text { Гагаринское } \\
\text { Gagarinskoe }\end{array}$ & 320 & 420 \\
\hline $\begin{array}{l}\text { Maговское } \\
\text { Magovskoe }\end{array}$ & 320 & 420 \\
\hline $\begin{array}{l}\text { им. Cухарева } \\
\text { behalf of Sukharev }\end{array}$ & 400 & 500 \\
\hline $\begin{array}{l}\text { Oзерное } \\
\text { Ozernoe }\end{array}$ & 440 & 500 \\
\hline $\begin{array}{l}\text { Баклановское } \\
\text { Baklanovskoe }\end{array}$ & 380 & 200 \\
\hline $\begin{array}{l}\text { Bинниковское } \\
\text { Vinnikovsky }\end{array}$ & 450 & 420 \\
\hline $\begin{array}{l}\text { Дороховское } \\
\text { Dorokhovskoe }\end{array}$ & 210 & 420 \\
\hline
\end{tabular}

Из табл. 3 и 4 видно, что различное содержание компонентов «кальцит-доломит-нерастворимый остаток» в горной породе оказывает существенное влияние на время нейтрализации кислотных составов. Проведе- ние таких исследований позволяет подобрать наиболее эффективную технологию (время выдержки композиции в пласте) проведения кислотного воздействия.

\section{Проведение фильтрационных исследований}

В качестве основного параметра, характеризующего эффективность кислотного воздействия по данным фильтрационных экспериментов, принята величина коэффициента изменения (восстановления) проницаемости (Кн2/Кн1). Данный коэффициент представляет собой отношение проницаемости образца керна по нефти после кислотного воздействия (Кн2) к значению этой проницаемости до воздействия (Кн1). Использовались образцы горных пород размером 30×30 мм.

В ходе экспериментов моделировались разнообразные условия проведения обработок для каждого из представленных месторождений: с наличием этапа выдержки состава в пласте $(1,2,4,6$ час) и с его отсутствием; с различными объемами закачиваемого состава $(1,2,4,6$ поровых объемов) и скоростями закачки. Каждый фильтрационный эксперимент дублировался (проведено порядка 300 исследований), в табл. 1 представлены результаты фильтрационных испытаний кислотных составов на образцах керна.

В табл. 5 стоит отметить отдельные эксперименты, которые сопровождались рентгенотомографическими исследованиями.

В одном случае на образце керна Озерного месторождения Составом 1 результаты эксперимента оказались неудачными - проницаемость несколько уменьшилась $(0,91)$. При этом совместный анализ результатов фильтрационных экспериментов и рент- 
геновской томографии образца керна обнаруживает весьма противоречивую ситуацию: с одной стороны, моделирование на образце кислотной обработки Сoставом 1 приводит к образованию весьма выраженного канала фильтрации (рис. 1); с другой - к снижению проницаемости образца по нефти. Причиной отмеченного явления может быть кольматация вновь образованного канала фильтрации продуктами, сопутствующими реакции, что весьма вероятно, учитывая шестичасовую выдержку состава в пласте.

Таблица 5. Результаты фильтрационных испытаний кислотных составов

Table 5. Results of filtration tests of acid compositions

\begin{tabular}{|c|c|c|c|c|}
\hline \multirow{2}{*}{$\begin{array}{c}\text { Месторождение } \\
\text { Field }\end{array}$} & \multirow{2}{*}{$\begin{array}{c}\text { Объем прокачки КС в объемах пор } \\
\text { Volume of pumping acid composition in } \\
\text { pore volumes }\end{array}$} & \multirow{2}{*}{$\begin{array}{c}\text { Тв, час } \\
\text { Holding time, } \\
\text { hour } \\
\end{array}$} & \multicolumn{2}{|c|}{$\mathrm{K}_{\mathrm{H}} 2 / \mathrm{K}_{н} 1$} \\
\hline & & & $\begin{array}{c}\text { Состав } 1 \\
\text { Composition } 1 \\
\end{array}$ & $\begin{array}{c}\text { Состав } 2 \\
\text { Composition } 2 \\
\end{array}$ \\
\hline \multirow{4}{*}{$\begin{array}{l}\text { Гагаринское } \\
\text { Gagarinskoe }\end{array}$} & 1 & $0 / 1 / 2 / 4 / 6$ & $1,1 / 1,2 / 1,8 / 1,1 / 0,06^{*}$ & $1,5 / 3,2 / 6,6 / 7,5 / 8,8$ \\
\hline & 2 & $0 / 1 / 2 / 4 / 6$ & $1,3 / 1,2 / 1,9 / 2,1 / 0,8$ & $1,5 / 2,5 / 3,8 / 6,8 / 1,6$ \\
\hline & 4 & $0 / 1 / 2 / 4 / 6$ & $0,38 / 0,8 / 7,1 / 5,5 / 7,8$ & $0,9 / 1,1 / 1,7 / 2,1 / 1,4$ \\
\hline & 6 & $0 / 1 / 2 / 4 / 6$ & $0,8 / 1,4 / 3,8 / 1,4 / 1,3$ & $1,8 / 6,4 / 8,1 / 5,4 / 6,1$ \\
\hline \multirow{4}{*}{$\begin{array}{l}\text { Маговское } \\
\text { Magovskoe }\end{array}$} & 1 & $0 / 1 / 2 / 4 / 6$ & $-/ 67 / 452 / 1204 / 8562,8$ & $11,2 / 45,3 / 34,9 / 55,6 / 98,6$ \\
\hline & 2 & $0 / 1 / 2 / 4 / 6$ & $-/ 124 / 6741 / 24554 / 56160$ & $144,7 / 188,5 / 253 / 2345 / 4771$ \\
\hline & 4 & $0 / 1 / 2 / 4 / 6$ & $-/ 89 / 684 / 2246 / 11254$ & $167 / 256 / 1542 / 2342 / 1984$ \\
\hline & 6 & $0 / 1 / 2 / 4 / 6$ & $-/ 145 / 542 / 986 / 1145$ & $142 / 159 / 223 / 1157 / 1845$ \\
\hline \multirow{4}{*}{$\begin{array}{c}\text { им. Сухарева } \\
\text { behalf of Sukharev }\end{array}$} & 1 & $0 / 1 / 2 / 4 / 6$ & $4,3 / 2,1 / 2,4 / 11,1 / 12,1$ & $18,1 / 5,6 / 2,4 / 3,1 / 3,2$ \\
\hline & 2 & $0 / 1 / 2 / 4 / 6$ & $1,3 / 10,5 / 24,2 / 12,1 / 11,2$ & $12,0 / 15,4 / 12,0 / 22,8 / 30,1$ \\
\hline & 4 & $0 / 1 / 2 / 4 / 6$ & $2,8 / 26,8 / 28,9 / 14,1 / 15,1$ & $1,1 / 2,4 / 14,2 / 28,4 / 24,4$ \\
\hline & 6 & $0 / 1 / 2 / 4 / 6$ & $1,2 / 54,9 / 88,6 / 54,2 / 100,3$ & $1,8 / 24,6 / 39,9 / 110,2 / 147,5$ \\
\hline \multirow{4}{*}{$\begin{array}{l}\text { Озерное } \\
\text { Ozernoe }\end{array}$} & 1 & $0 / 1 / 2 / 4 / 6$ & $-/ 24,5 / 310,1 / 679,2 / 399,1$ & $15,4 / 49,6 / 87,6 / 100,2 / 935,4$ \\
\hline & 2 & $0 / 1 / 2 / 4 / 6$ & $-154,1 / 245,1 / 648,6 / 0,9$ & $102 / 468,5 / 864,2 / 1195,3 / 2297$ \\
\hline & 4 & $0 / 1 / 2 / 4 / 6$ & $-/ 26,8 / 201,4 / 354,8 / 21,5$ & $84,1 / 14,2 / 102,5 / 144,5 / 365,4$ \\
\hline & 6 & $0 / 1 / 2 / 4 / 6$ & $-/ 15,4 / 54,6 / 87,6 / 98,6$ & $74,6 / 164,2 / 188,4 / 674,5 / 721,2$ \\
\hline \multirow{4}{*}{$\begin{array}{l}\text { Баклановское } \\
\text { Baklanovskoe }\end{array}$} & 1 & $0 / 1 / 2 / 4 / 6$ & $-/ 134,1 / 6,7 / 79,3 / 122,1$ & $13,2 / 33,3 / 114,7 / 133,5$ \\
\hline & 2 & $0 / 1 / 2 / 4 / 6$ & $-/ 40,4 / 1344,3 / 39487,9 /-$ & $29,8 / 86,0 / 250,7 / 336,6$ \\
\hline & 4 & $0 / 1 / 2 / 4 / 6$ & $-/ 176,6 / 245,6 / 252,6 / 301$ & $97,1 / 388,1 / 476,8 / 501,8$ \\
\hline & 6 & $0 / 1 / 2 / 4 / 6$ & $-/ 89,6 / 122,5 / 345,1 / 894,1$ & $101,2 / 254,5 / 653,1 / 687,5$ \\
\hline \multirow{4}{*}{$\begin{array}{l}\text { Винниковское } \\
\text { Vinnikovskoe }\end{array}$} & 1 & $0 / 1 / 2 / 4 / 6$ & $-/ 3,9 / 15,1 / 22,1 / 31,5$ & $1,2 / 7,4 / 11,2 / 68,7 / 169,3$ \\
\hline & 2 & $0 / 1 / 2 / 4 / 6$ & $-/ 12,1 / 77,2 / 180,5 / 2011$ & $6,7 / 221,4 / 754,1 / 1120,5 / 1568$ \\
\hline & 4 & $0 / 1 / 2 / 4 / 6$ & $-/ 22,8 / 29,8 / 15,3 / 30,1$ & $5,4 / 8,5 / 146,7 / 574,6 / 1214,3$ \\
\hline & 6 & $0 / 1 / 2 / 4 / 6$ & $-/ 24,5 / 56,8 / 77,4 / 154,7$ & $4,1 / 15,7 / 87,6 / 351,2 / 364,1$ \\
\hline \multirow{4}{*}{$\begin{array}{l}\text { Дороховское } \\
\text { Dorokhovskoe }\end{array}$} & 1 & $0 / 1 / 2 / 4 / 6$ & $7,3 / 55,2 / 156,4 / 253,1$ & $7,5 / 98,6 / 360,7 / 146,7$ \\
\hline & 2 & $0 / 1 / 2 / 4 / 6$ & $5,1 / 170,8 / 374,5 / 386,0$ & $32,5 / 88,4 / 129,2 / 2931,9$ \\
\hline & 4 & $0 / 1 / 2 / 4 / 6$ & $18,9 / 411,2 / 7805,5 / 10416$ & $244,1 / 988,5 / 2441,2 / 3423,0$ \\
\hline & 6 & $0 / 1 / 2 / 4 / 6$ & $41,2 / 2344,2 / 6875,9 / 5542$ & $111,2 / 1564,8 / 4289,4 / 1201,1$ \\
\hline
\end{tabular}

Примечание: * указано среднее значение.

Note: * average value.

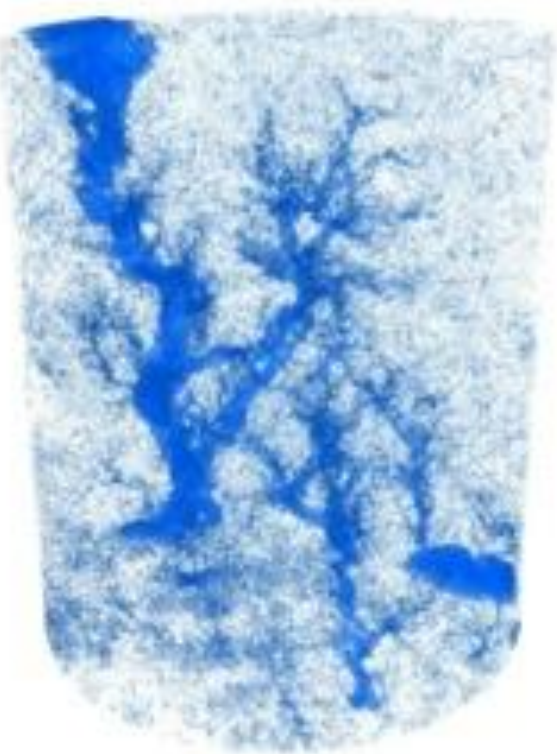

Pис. 1. Изображение образиа керна после шестичасовой выдержки кислотного состава 1

Fig. 1. Core sample image in six hours of shutter of acid composition no. 1
Для оценки данного предположения на представленном образце керна после повторной экстракции проведены фильтрационные испытания с определением проницаемости по нефти. Коэффициент восстановления проницаемости в данном случае составил 7000 , указывая на кольматацию ранее образованного канала продуктами, сопутствующими реакции. Проведенные опыты позволяют говорить о том, что увеличение времени выдержки не всегда приводит к более существенной эффективности обработки [21-24].

Для Маговского и Баклановского месторождений отмечается тенденция увеличения коэффициента проницаемости при росте объема закачиваемого кислотного состава при его выдержке в пласте. Как видно из рис. 2 , после моделирования кислотного воздействия на образцах получены значительные по размерам каналы фильтрации - «червоточины».

Для месторождения им. Сухарева отмечается низкая эффективность составов, которая, вероятно, связана с невысокой карбонатностью и существенной глинистостью горной породы. Сравнительный анализ представленных на рис. 3 моделей образца до и после кислотной обработки позволяет сделать вывод об 
увеличении общей пустотности (до 23 \%) и проницаемости (в 2,4 раза).

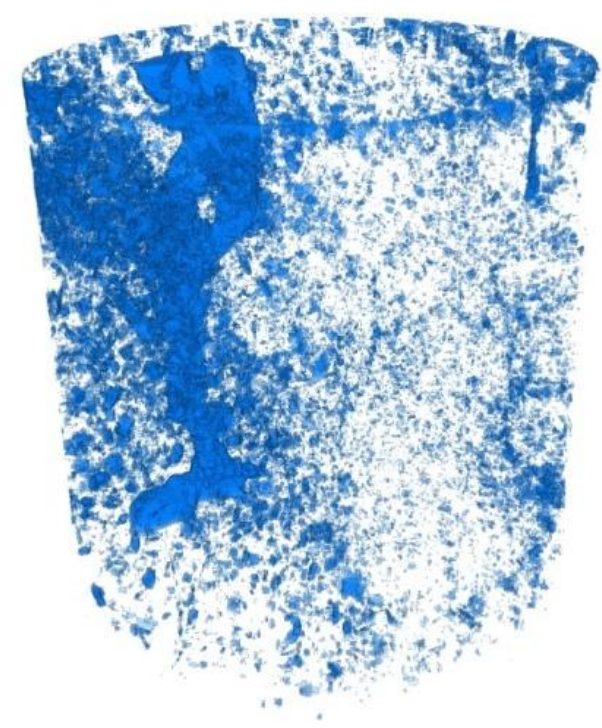

Рис. 2. Результатьл томографических исследований образиа Баклановского месторождения после кислотного воздействия

Fig. 2. Image of core sample from the Baklanovskoe field after acid exposure

Также интересные результаты получены при проведение фильтрационных экспериментов на образцах керна Гагаринского месторождения. Из результатов, представленных в таблице, видно, что ни в одном случае опыты не привели к сколь значимому результату. В целом эффективность кислотного воздействия можно считать низкой (рис. 4).

По результатам исследований кислотных составов отмечено, что увеличение скорости закачки приводит к росту коэффициента проницаемости по нефти после кислотной обработки (рис. 5) [25-32].

На основе фильтрационных и томографических испытаний сформированы рекомендации по эффективному применению кислотных составов на рассматриваемых месторождениях, которые представлены в табл. 6.

\section{Анализ проведенных кислотных обработок на Баклановском и Гагаринском месторождениях}

По рекомендациям, представленным в табл. 6, проведены кислотные обработки Составом 1 на Баклановском месторождении с двух, трех и четырех часовой выдержкой в пласте, объем кислотного состава во всех случаях составлял $2 \mathrm{~m}^{3} / \mathrm{M}$. Интервалы изменений и средние значения показателей технологической эффективности обработок представлены в табл. 7. В таблице также представлены результаты ранее проведенных кислотных обработок Составом 1 с указанным объемом состава при шестичасовой выдержке в пласте.

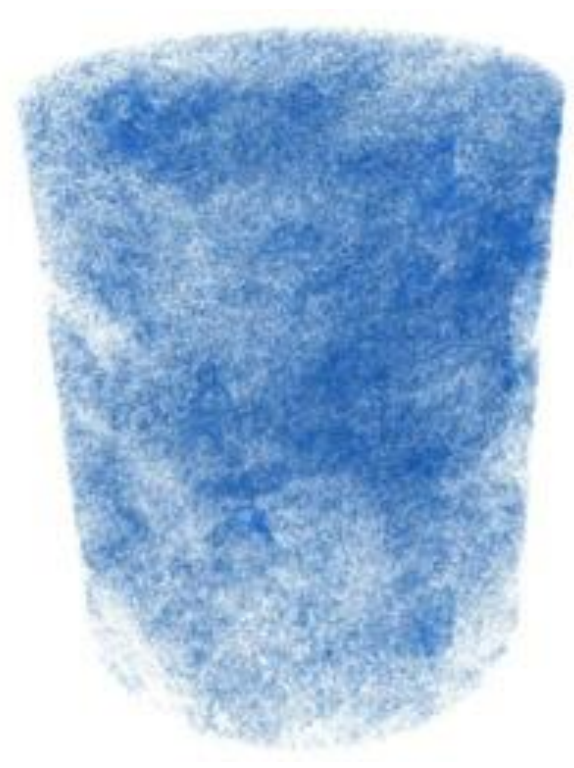

$a / a$

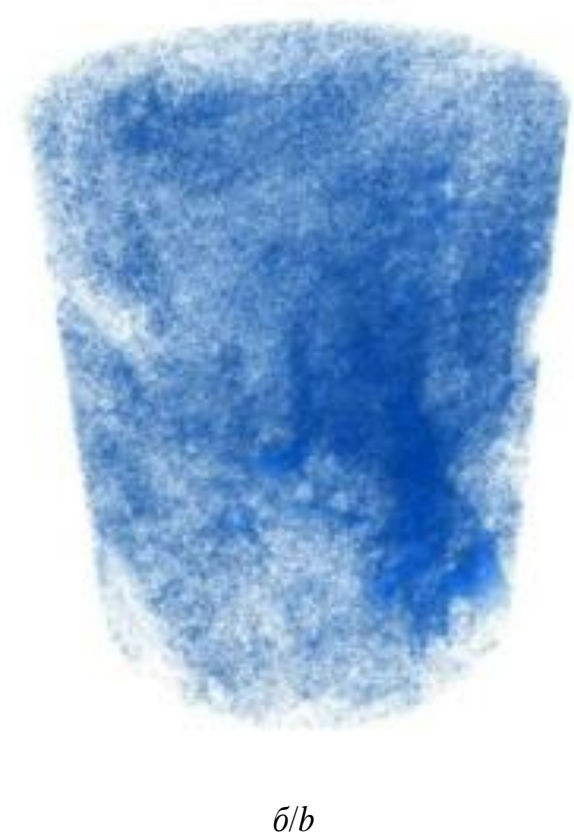

$\sigma / b$

Pис. 3. Изображение образца керна месторождения им. Сухарева: а) до кислотного воздействия; б) после кислотного воздействия

Fig. 3. Image of the core sample field Sukharev: a) before acid exposure; b) after acid exposure 


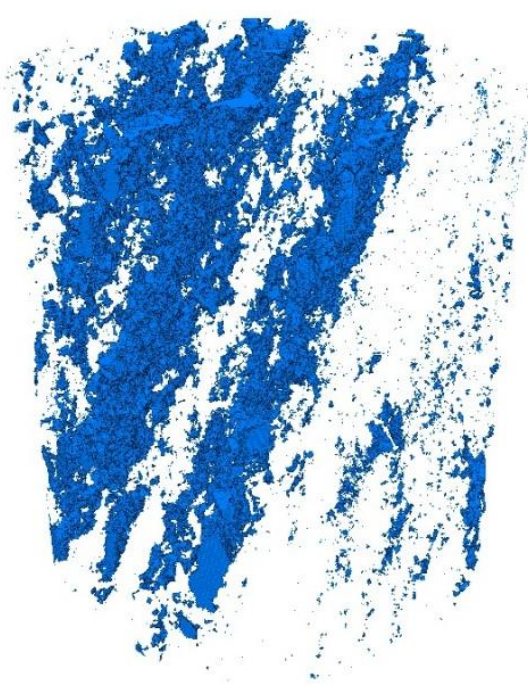

ala

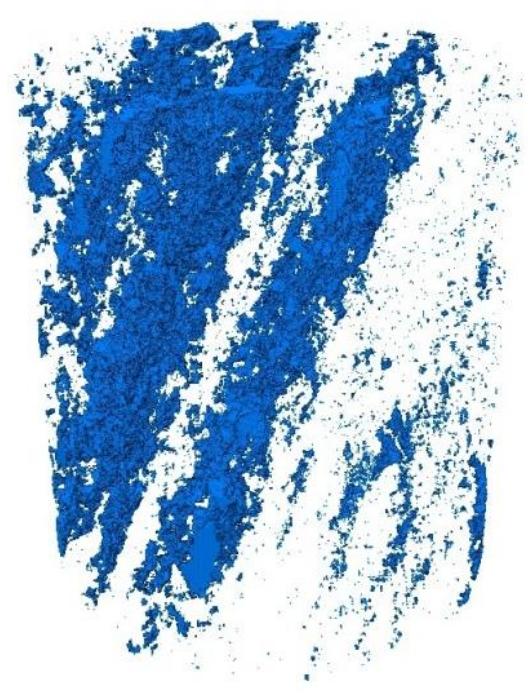

$6 / b$

Рис. 4. Результаты томографических исследований образиа Гагаринского месторождения: а) до кислотного воздействия; б) после кислотного воздействия

Fig. 4. Image of core sample from the Gagarinskoe field: a) before acid exposure; b) after acid exposure



Pис. 5. Зависимость проницаемости образиов по нефти после кислотной обработки от скорости закачки кислотных составов

Fig. 5. Dependence of permeability of the samples for oil after acid treatment on injection rate of acid compositions

Таблица 6. Рекомендации по применению кислотных составов для обработок на рассматриваемых объектах Table 6. Recommendations for using acidic compositions for treatments at the studied sites

\begin{tabular}{|c|c|c|c|c|}
\hline \multirow{2}{*}{$\begin{array}{c}\text { Месторождение } \\
\text { Field }\end{array}$} & \multicolumn{2}{|c|}{$\begin{array}{l}\text { Продолжительность выдержки, час } \\
\text { Holding time, hour }\end{array}$} & \multicolumn{2}{|c|}{$\begin{array}{c}\text { Объем состава, } \mathrm{m}^{3} / \mathrm{M} \\
\text { Volume of composition, } \mathrm{m}^{3} / \mathrm{m}\end{array}$} \\
\hline & $\begin{array}{c}\text { Состав № } 1 \\
\text { Composition № } 1\end{array}$ & $\begin{array}{c}\text { Состав № } 2 \\
\text { Composition № } 2\end{array}$ & $\begin{array}{c}\text { Состав № } 1 \\
\text { Composition № } 1\end{array}$ & $\begin{array}{c}\text { Состав № } 2 \\
\text { Composition № } 2\end{array}$ \\
\hline $\begin{array}{c}\text { Гагаринское } \\
\text { Gagarinskoe }\end{array}$ & $\begin{array}{c}\text { бeз } \\
\text { without }\end{array}$ & $\begin{array}{c}\text { бes } \\
\text { without }\end{array}$ & $\begin{array}{c}\text { до } 1 \\
\text { up to } 1\end{array}$ & $\begin{array}{c}\text { до } 2 \\
\text { up to } 2\end{array}$ \\
\hline $\begin{array}{l}\text { Маговское } \\
\text { Magovskoe }\end{array}$ & $\begin{array}{c}\text { до } 6 \\
\text { up to } 6\end{array}$ & $\begin{array}{c}\text { до } 6 \\
\text { up to } 6\end{array}$ & $\begin{array}{c}\text { до } 2 \\
\text { up to } 2 \\
\end{array}$ & $\begin{array}{c}\text { до } 2 \\
\text { up to } 2 \\
\end{array}$ \\
\hline $\begin{array}{c}\text { им. Сухарева } \\
\text { behalf of Sukharev }\end{array}$ & $\begin{array}{c}\text { до } 2 \\
\text { up to } 2 \\
\end{array}$ & $\begin{array}{c}\text { без } \\
\text { without }\end{array}$ & $\begin{array}{c}\text { до } 2 \\
\text { up to } 2 \\
\end{array}$ & $\begin{array}{c}\text { до } 2 \\
\text { up to } 2 \\
\end{array}$ \\
\hline $\begin{array}{l}\text { Озерное } \\
\text { Ozernoe }\end{array}$ & $\begin{array}{c}\text { до } 4 \\
\text { up to } 4\end{array}$ & $\begin{array}{c}\text { до } 8 \\
\text { up to } 8\end{array}$ & $\begin{array}{c}\text { до } 1 \\
\text { up to } 1\end{array}$ & $\begin{array}{c}\text { до } 2 \\
\text { up to } 2\end{array}$ \\
\hline $\begin{array}{l}\text { Баклановское } \\
\text { Baklanovskoe }\end{array}$ & $\begin{array}{c}\text { до } 4 \\
\text { up to } 4\end{array}$ & $\begin{array}{c}\text { до } 4 \\
\text { up to } 4\end{array}$ & $\begin{array}{c}\text { до } 4 \\
\text { up to } 4\end{array}$ & $\begin{array}{c}\text { до } 4 \\
\text { up to } 4\end{array}$ \\
\hline $\begin{array}{c}\text { Винниковское } \\
\text { Vinnikovskoe }\end{array}$ & $\begin{array}{c}\text { до } 6 \\
\text { up to } 6\end{array}$ & $\begin{array}{c}\text { до } 2 \\
\text { up to } 2 \\
\end{array}$ & $\begin{array}{c}\text { до } 2 \\
\text { up to } 2 \\
\end{array}$ & $\begin{array}{c}\text { до } 1 \\
\text { up to } 1 \\
\end{array}$ \\
\hline $\begin{array}{l}\text { Дороховское } \\
\text { Dorokhovskoe }\end{array}$ & $\begin{array}{c}\text { до } 4 \\
\text { up to } 4\end{array}$ & $\begin{array}{c}\text { до } 4 \\
\text { up to } 4 \\
\end{array}$ & $\begin{array}{c}\text { до } 6 \\
\text { up to } 6 \\
\end{array}$ & $\begin{array}{c}\text { до } 6 \\
\text { up to } 6 \\
\end{array}$ \\
\hline
\end{tabular}


Таблица 7. Эффективность проведенных кислотных обработок Составом 1 на Баклановском месторождении Table 7. Effectiveness of acid treatments with composition no. 1 at the Baklanovskoe field

\begin{tabular}{|c|c|c|c|c|}
\hline \multirow[t]{3}{*}{$\begin{array}{l}\text { Показатель эффективности } \\
\text { Performance indicator }\end{array}$} & \multirow{2}{*}{\multicolumn{4}{|c|}{$\begin{array}{c}\text { Значение показателя эффективности } \\
\text { (числитель - интервал изменения; знаменатель - среднее значение) } \\
\text { Significance efficiency } \\
\text { (numerator - change interval; denominator - average value) }\end{array}$}} \\
\hline & & & & \\
\hline & 2 & 3 & 4 & 6 \\
\hline $\begin{array}{l}\text { Фактический прирост дебита нефти, т/сут } \\
\text { Actual oil flow rate, t/day }\end{array}$ & $\frac{1,7-5,3}{3,4}$ & $\frac{0,3-5,2}{3,2}$ & $\frac{1,9-8,6}{4,3}$ & $\frac{0,9-3,6}{2,6}$ \\
\hline $\begin{array}{l}\text { Удельный фактический прирост дебита нефти, т/(сут } \cdot \text { м) } \\
\text { Specific actual increase in oil production rate, } \mathrm{t} /(\text { day·m })\end{array}$ & $\frac{0,32-2,62}{1,05}$ & $\frac{0,05-2,17}{1,02}$ & $\frac{0,12-5,12}{1,07}$ & $\frac{0,10-2,02}{0,90}$ \\
\hline $\begin{array}{l}\text { Время работы с эффектом, сут. } \\
\text { Time of work with the effect, day }\end{array}$ & $\frac{13,5-229,6}{127,1}$ & $\frac{7,0-285,6,0}{123,0}$ & $\frac{16,4-205,5}{123,3}$ & $\frac{12,2-209,9}{108,5}$ \\
\hline $\begin{array}{l}\text { Доп. добыча нефти, т } \\
\text { Additional oil production, tons }\end{array}$ & $\frac{37,7-180,9}{89,6}$ & $\frac{34,2-254,2}{94,5}$ & $\frac{48,9-289,5}{116,2}$ & $\frac{24,5-227,1}{86,8}$ \\
\hline $\begin{array}{l}\text { Количество операций } \\
\text { Number of operations }\end{array}$ & 9 & 7 & 8 & 7 \\
\hline
\end{tabular}

Как следует из анализа представленных в таблице данных, показатели технологической эффективности для обработок, выполненных с четырехчасовой выдержкой кислотного Состава 1 в пласте, имеют большие значения, чем для обработок с шестичасовой выдержкой, которые применялись ранее: фактический прирост дебита увеличился на $65 \%$ (с 2,6 до 4,3 т/сут), средняя дополнительная добыча нефти на 33 \% (с 86,8 до 116,2 т/сут), продолжительность эффекта на 13 \% (с 108,5 до 123,3 суток).
Составом 2 проведены кислотные обработки на Гагаринском месторождении с объемом кислотного состава $2 \mathrm{~m}^{3} / \mathrm{m}$; обработки проводились без выдержки кислотного состава в пласте. На рис. 6 представлена зависимость среднего прироста дебита нефти после проведения кислотной обработки Составом 2 от продолжительности выдержки состава в пласте, а также эффективность ранее проведенных кислотных обработок.

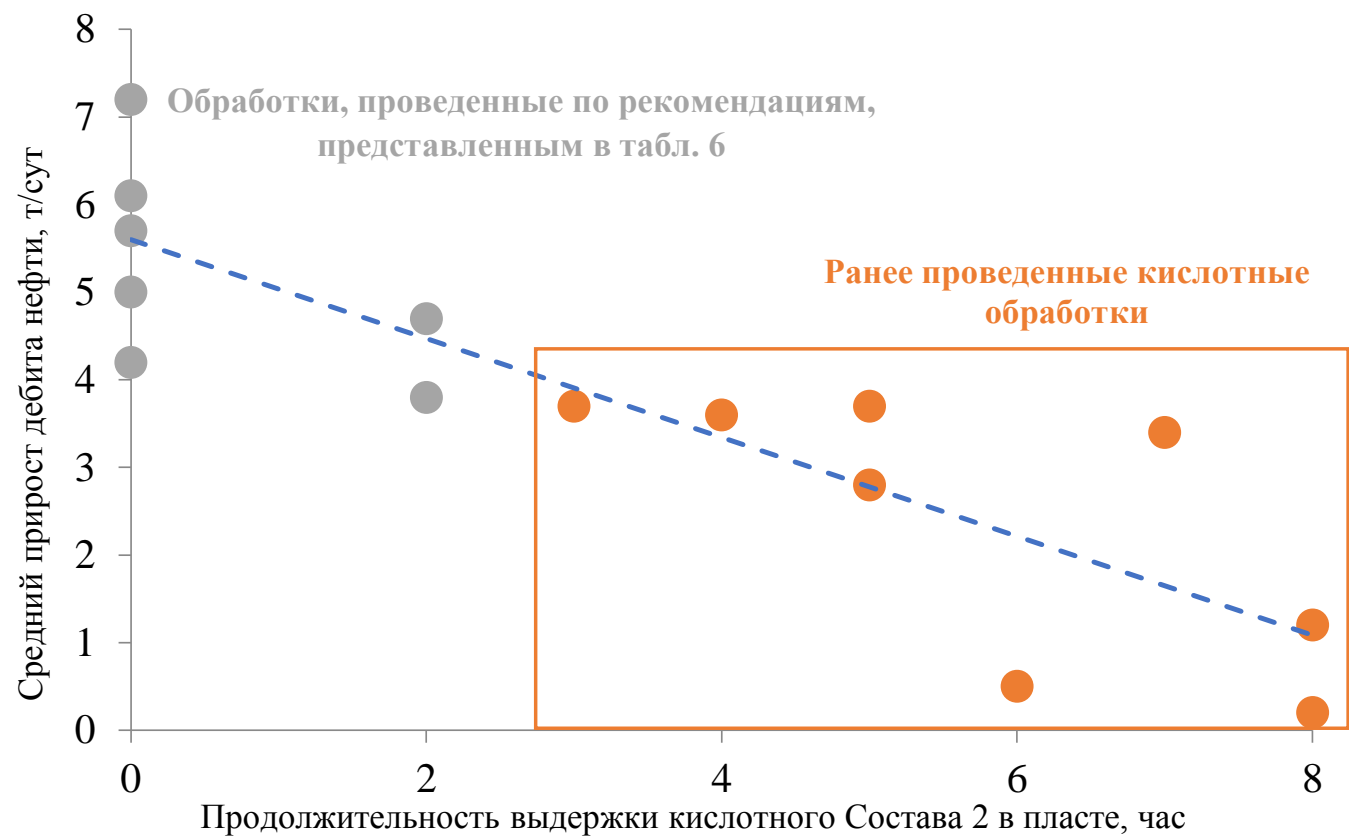

Рис. 6. Зависимость между средним приростом дебита нефти после кислотной обработки Составом 2 от времени выдержки его в пласте

Fig. 6. Relationship between the average daily increase of the composition after acid treatment no. 2 on its holding time in reservoir

Как следует из анализа представленных на рис. 6 данных, по скважинам, на которых проведены обработки Составом 2 без его выдержки в пласте на реакцию, получены более существенные значения прироста дебита нефти (в среднем увеличение на $55 \%$ ), чем у ранее проведенных обработок с выдержкой от 3 до
8 часов. Сокращение продолжительности периода выдержки кислотного состава в пласте приводит к снижению потерь добычи нефти вследствие простоя скважин на проведение мероприятия и к увеличению технологической эффективности (прирост дебита нефти) кислотного воздействия. 


\section{Заключение}

По данным фильтрационных и рентгенотомографических экспериментов подобраны условия эффективного применения двух кислотных составов для карбонатных объектов Гагаринского, Маговского, им. Сухарева, Озерного, Баклановского, Винниковского и Дороховского месторождений, отличающихся содержанием компонентов в горной породе «кальцитдоломит-нерастворимый остаток». Обобщение всех результатов позволило разработать рекомендации по оптимизации технологических параметров проведения обработок на рассматриваемых объектах, что, в свою очередь, приведет к снижению потерь добычи нефти вследствие простоя скважин на проведение мероприятия и к увеличению среднего прироста дебита скважин. Предложенные рекомендации по изме-

\section{СПИСОК ЛИТЕРАТУРЫ}

1. Новиков В.А., Мартюшев Д.А. Опыт применения кислотных составов в карбонатных отложениях нефтяных месторождений Пермского края // Вестник Пермского национального исследовательского политехнического университета. Геология. Нефтегазовое и горное дело. - 2020. - Т. 20. - № 1. - С. $72-87$.

2. Распопов А.В., Новокрещенных Д.В. Анализ результатов применения методов интенсификации на карбонатных коллекторах месторождений Пермского края // Вестник Пермского национального исследовательского политехнического университета. Геология. Нефтегазовое и горное дело. - 2014. № 10. - C. 73-82.

3. Modeling and simulation of wormhole formation during acidization of fractured carbonate rocks / Piyang Liu, Jun Yao, Gary Douglas Couples, Jingsheng Ma, Hai Sun // Journal of Petroleum Science and Engineering. - June 2017. - V. 154. - P. 284-301.

4. Кристиан М., Сокол С., Константинеску А. Увеличение продуктивности и приемистости скважин. - М.: Недра, 1985. $84 \mathrm{c}$.

5. Иванов С.И. Интенсификация притока нефти и газа к скважинам. - М.: ООО «Недра-Бизнесцентр», 2006. - 565 с.

6. Дзюбенко А.И., Никонов А.Н., Мерсон М.Э. Информационный способ повышения эффективности методов воздействия на призабойную зону пласта в действующих скважинах // Вестник Пермского национального исследовательского политехнического университета. Геология. Нефтегазовое и горное дело. - 2017. - Т. 16. - № 2. - С. 148-158.

7. Механический комплекса защиты пласта и технология его применения для предотвращения кольматации призабойной зоны пласта в процессе проведения геолого-технических мероприятий / В.В. Пепеляев, И.Л. Коробков, Д.В. Пепеляев, А.М. Насыров, С.В. Галкин // Вестник Пермского национального исследовательского политехнического университета. Геология. Нефтегазовое и горное дело. - 2016. - Т. 15. № 21. - C. 329-339.

8. Моделирование кислотной обработки призабойной зонь скважины с учетом еe ухудшенных фильтрационноемкостных характеристик (часть 1) / К.А. Турегелдиева, У.К. Жалбасбаев, Б.К. Асилбеков, А.Б. Золотухин // Нефтяное хозяйство. - 2016. - № 1. - С. 50-54.

9. Дорфман М.Б., Сентемов А.А. Влияние фильтрационноемкостных свойств призабойной зоны пласта на эффективность кислотной обработки // Известия Томского политехнического университета. Инжиниринг георесурсов. - 2020. T. 331. - № 2. - C. 124-130.

10. Мирзаджанзаде А.Х. Технология и техника добычи нефти. М.: Недра, 1985. $-385 \mathrm{c}$.

11. Савицкий Я.В. Современные возможности метода рентгеновской томографии при исследовании керна нефтяных и газовых месторождений // Вестник Пермского национального исследовательского политехнического университета. Геология. Нефтегазовое и горное дело. - 2015. - № 15. - С. 28-37. нению дизайна кислотного воздействия были осуществлены на двух исследуемых месторождениях. Показатели технологической эффективности для ранее используемого дизайна кислотного воздействия в некоторых случаях оказались существенно ниже, чем при предложенной технологии. Таким образом, удалось сократить потери нефти за счет снижения простоя скважины на проведение мероприятия и увеличить прирост дебита нефти.

Применение рентгеновской томографии позволило выделить случаи, для которых в результате воздействия характерен прирост пустотности, но снижение проницаемости. Данный факт позволит проводить дальнейшие работы по совершенствованию рецептур составов и технологий их применения.

12. X-ray microtomography of hydrochloric acid propagation in carbonate rocks / A.C. Machado, T.J.L. Oliveira, F.B. Cruz, R.T. Lopes, I. Lima // Applied Radiation and Isotopes. - February 2015. - V. 96. - P. 129-134

13. Numerical simulation and $\mathrm{X}$-ray imaging validation of wormhole propagation during acid core-flood experiments in a carbonate gas reservoir / Alireza Safari, Mojtaba Moradi Dowlatabad, Ali Hassani, Fariborz Rashidi // Journal of Natural Gas Science and Engineering. - March 2016. - V. 30. - P. 539-547.

14. Naizhen Liu, Ming Liu. Simulation and analysis of wormhole propagation by VES acid in carbonate aciding // Journal of Petroleum Science and Engineering. - February 2016. - V. 138. P. 57-65.

15. Christophe Snoeck, Maura Pellegrini. Comparing bioapatite carbonate pre-treatments or isotopic measurements: Part 1. Impact on structure and chemical composition // Chemical Geology. 6 December 2015. - V. 417. - P. 394-403.

16. Burgos-Cara A., Ruiz-Agudo E., Rodriguez-Navarro C. Effectiveness of oxalic acid treatmets for the protection of marble surfaces // Materials \& Design. - 5 February 2017. - V. 115. P. 82-92.

17. Мартюшев Д.А. Лабораторные исследования кислотных составов для обработки коллекторов, характеризующихся различной карбонатностью и структурой пустотного пространства // Известия Томского политехнического университета. Инжиниринг георесурсов. - 2018. - Т. 329. - № 4. - С. 6-12.

18. Lan-Anh Phan Thi, Huu-Tuan Do, Shang-Lien Lo. Enhancing decomposition rate of perfluorooctanoic acid by carbonate radical assisted sonochemical treatment // Ultrasonics Sonochemistry. September 2014. - V. 21. - Iss. 5. - P. 1875-1880.

19. Tomohito Kameda, Masahito Tochinai, Toshiaki Yoshioka. Treatment of hydrochloric acid using $\mathrm{Mg}-\mathrm{Al}$ layered double hydroxide intercalated with carbonate // Journal of Industrial and Engineering Chemistry. - 25 July 2016. - V. 39. - P. 21-26.

20. Sustainability analysis of dry treatment technologies for acid gas removal in waste-to-energy plants / A. Dal Pozzo, D. Guglielmi, G. Antonioni, A. Tugnoli // Journal of Cleaner Production. - 20 September 2017. - V. 162. - P. 1061-1074.

21. Application status and research progress of shale reservoirs acid treatment technology / Nianyin Li, Jinxin Dai, Jianhui Li, Fengjun Bai, Zhifeng Luo // Natural Gas Industry B. - March 2016. V. 3. - Iss. 2. - P. 165-172.

22. Effect of acid treatment on the characteristics and structures of high-sulfur bituminous coal / Lanjun Zhang, Zenghua Li, Yongliang Yang, Yinbo Zhou, Leilei Si // Fuel. - 15 November 2016. - V. 184. - P. 418-429.

23. Рогачев М.К., Мухаметшин В.В. Контроль и регулирование процесса солянокислотного воздействия на призабойную зону скважин по геолого-промысловым данным // Записки Горного института. - 2018. - Т. 231. - С. 275-280.

24. Мухаметшин В.В. О необходимости и создании единого комплексного метода геолого-промыслового анализа и обобщения 
эффективности воздействия на призабойную зону пласта // Нефтяное хозяйство. - 2017. - № 4. - С. 80-84.

25. Научный инжиниринг как основа процессов моделирования при разработке месторождений / М.М. Хасанов, А.Н. Ситников, А.А.Пустовских, А.П. Рощектаев, Н.С. Исмагилов, Г.В. Падерин, Е.В. Шель // Георесурсы. - 2018. - Т. 20. - № 3. C. $142-148$.

26. Грезина О.А., Уметбаев В.Г. Оценка условий эффективного применения кислотно-имплозионного воздействия на призабойную зону пласта // Геология, геофизика и разработка нефтяных и газовых месторождений. - 2018. - № 2. - С. 60-66.

27. Зейгман Ю.В., Сергеев В.В., Аюпов Р.Р. Классификация физико-химических методов интенсификации добычи нефти по механизму воздействия на пластовую систему // Геология, геофизика и разработка нефтяных и газовых месторождений. - 2017. - № 1. - С. 50-53.

28. An experimental study on acid-rock reaction kinetics using dolomite in carbonate acidizing / Hyunsang Yoo, Youngmin Kim, Wonsuk Lee, Jeonghwan Lee // Journal of Petroleum Science and Engineering. - 2018. - V. 168. - P. 478-494.
29. Mohamed Mahmoud, Assad Barri, Salaheldin Elkatatny. Mixing chelating agents with seawater for acid stimulation treatment in carbonate reservoirs // Journal of Petroleum Science and Engineering. - 2017. - V. 152. - P. 9-20.

30. Увеличение нефтеотдачи залежей высоковязких нефтей кислотными композициями на основе поверхностно-активных веществ, координирующих растворителей и комплексных соединений / Л.К. Алтунина, В.А. Кувшинов, Л.А. Стасьева, И.В. Кувшинов // Георесурсы. - 2019. - Т. 21. - № 4. - С. 103-113.

31. Хузин Р.А., Хижняк Г.П. Лабораторные исследования влияния концентрации и скорости закачки кислоты на развитие червоточин при пластовых условиях // Вестник Пермского национального исследовательского политехнического университета. Геология. Нефтегазовое и горное дело. - 2019. T. 19. - № 4. - C. 356-372.

32. Шакен М.Ш. Исследование применимости кислотной обработки в конгломератных коллекторах // SOCAR Proceedings. 2019. - № 4. - C. 23-31.

Поступила 13.03.2020 2.

\section{Информация об авторах}

Мартюшев Д.А., кандидат технических наук, доцент кафедры нефтегазовых технологий Пермского национального исследовательского политехнического университета.

Новиков В.А., инженер 2-й категории отдела проектирования и мониторинга разработки Осинской и Кунгурской группы месторождений филиала ООО «ЛУКОЙЛ-Инжиниринг» «ПермНИПИнефть» в г. Перми. 
UDC 622.276

\title{
IMPROVING ACIDIZING IN THE COLLECTORS CHARACTERIZED BY DIFFERENT CARBONATE CONTENT (ON THE EXAMPLE OF OIL FIELDS OF PERM KRAI)
}

\author{
Dmitry A. Martyushev1, \\ martyushevd@inbox.ru \\ Vladimir A. Novikov², \\ novikov.vladimir.andr@gmail.com \\ 1 Perm National Research Polytechnic University, \\ 29, Komsomolskiy avenue, Perm, 614990, Russia. \\ 2 Branch of $\mathrm{OOO}$ «LUKOIL-Engineering» «PermNIPIneft» in Perm, \\ 29, Sovetskoy Armii street, Perm, 614000, Russia.
}

The relevance of the work is caused by the fact that the technological parameters of the acid treatment, such as holding time in the reservoir and the volume of composition, significantly affect the result of the geological and technical measure. According to many experts, it is necessary to study the issue of the need for an acid stage in the reservoir and its duration in the technological process of processing. The specific volume of acid is determined by various factors, such as rock composition, the bottomhole zone properties, the desired depth of acid penetration into the reservoir, etc.

The main aim of the study is to assess the impact of the technological parameters of acid treatments on the effectiveness of geological and technical measure in the oil fields of the Perm region.

The method of study is the laboratory experiments using a device for determining the carbonate content of rocks - the carbonatomer KM-04M, filtration units with simulation of formation conditions of UIP-5VG and AFS-300, as well as the units of microfocus fluoroscopy.

The results. An acid exposure was performed using two compositions to determine the return permeability and X-ray tomographic studies for different «calcite-dolomite-insoluble residue» components of the core samples from deposits in the Perm region. X-ray tomographic experiments were performed twice on each core sample: before and after the acid treatment. The conditions for the effective use of acidic formulations in the oil fields under consideration were selected based on the results of filtration and X-ray tomographic studies. Summation of all the research results allowed developing recommendations for optimizing the technological parameters of acid treatments at the considered production target. The use of $X$-ray tomography made it possible to distinguish cases for which, as a result of acid exposure, an increase in the volume of void space is observed with a decrease in permeability. This fact will allow further work to improve the formulation of acid compositions and technologies for their use.

\section{Key words:}

Acid treatments, carbonate reservoirs, filtration research, tomography studies, coefficient of permeability recovery, technological parameters, holding time in reservoir, amount of injected composition, technological efficiency.

\section{REFERENCES}

1. Novikov V.A., Martyushev D.A. Experience of using acid compositions in carbonate deposits of oil fields in the Perm region. Bulletin of the Perm National Research Polytechnic University. Geology. Oil and gas and mining, 2020, vol. 20, no. 1, pp. 72-87. In Rus.

2. Raspopov A.V., Novokreshchennykh D.V. Analysis of the results of the use of intensification methods on carbonate reservoirs of the Perm Territory fields. Bulletin of the Perm National Research Polytechnic University. Geology. Oil and gas and mining, 2014 no. 10, pp. 73-82. In Rus.

3. Piyang Liu, Jun Yao, Gary Douglas Couples, Jingsheng Ma, Hai Sun. Modeling and simulation of wormhole formation during acidization of fractured carbonate rocks. Journal of Petroleum Science and Engineering, June 2017, vol. 154, pp. 284-301.

4. Christian M., Sokol S., Constantinescu A. Uvelichenie produktivnosti i priemistosti skvazhin [Increased well productivity and injectivity]. Moscow, Nedra Publ., 1985. 84 p.

5. Ivanov S.I. Intensifikatsiya pritoka nefti $i$ Gaza k skvazhinam [Intensification of oil and gas inflow to wells]. Moscow, LLC Nedra-Business Center Publ., 2006. 565 p.

6. Dzyubenko A.I., Nikonov A.N., Merson M.E. Information way to improve the efficiency of methods to influence the bottomhole formation zone in the existing wells. Bulletin of Perm National Research Polytechnic University. Geology. Oil and gas and mining, 2017, vol. 16, no. 2, pp. 148-158. In Rus.

7. Pepelyaev V.V., Korobkov I.L., Pepelyaev D.V., Nasyrov A.M., Galkin S.V. Mechanical complex of reservoir protection and the technology of its use to prevent clogging of the bottomhole formation zone in the process of geological and technical measures.
Bulletin of the Perm National Research Polytechnic University. Geology. Oil and gas and mining, 2016, vol. 15, no. 21, pp. 329-339. In Rus.

8. Turegeldiev K.A., Zhalbasbaev U.K., Asilbekov B.K., Zolotukhin A.B. Modeling of acid treatment of the well bottom zone taking into account its degraded reservoir characteristics (part 1). Oil industry, 2016, no. 1, pp. 50-54. In Rus.

9. Dorfman M.B., Sentemov A.A. Influence of reservoir properties of the bottomhole formation zone on the efficiency of acid treatment. Bulletin of the Tomsk Polytechnic University. Geo Assets Engineering, 2020, vol. 331, no. 2, pp. 124-130. In Rus.

10. Mirzadzhanzade A.Kh. Tekhnologiya i tekhnika dobychi nefti [Oil production technique]. Moscow, Nedra Publ., 1985. 385 p.

11. Savitsky Ya.V. Modern possibilities of the method of X-ray tomography in the study of core oil and gas fields. Bulletin of the Perm National Research Polytechnic University. Geology. Oil and gas and mining, 2015, no. 15, pp. 28-37. In Rus.

12. Machado A.C. Oliveira T.J.L., Cruz F.B., Lopes R.T., Lima I. $\mathrm{X}$-ray microtomography of hydrochloric acid propagation in carbonate rocks. Applied Radiation and Isotopes, February 2015, vol. 96, pp. 129-134.

13. Alireza Safari, Mojtaba Moradi Dowlatabad, Ali Hassani, Fariborz Rashidi. Numerical simulation and X-ray imaging validation of wormhole propagation during acid core-flood experiments in a carbonate gas reservoir. Journal of Natural Gas Science and Engineering, March 2016, vol. 30, pp. 539-547.

14. Naizhen Liu, Ming Liu. Simulation and analysis of wormhole propagation by VES acid in carbonate aciding. Journal of Petroleum Science and Engineering, February 2016, vol. 138, pp. 57-65. 
15. Christophe Snoeck, Maura Pellegrini. Comparing bioapatite carbonate pre-treatmets or isotopic measurements: Part 1 - Impact on structure and chemical composition. Chemical Geology, 6 December 2015, vol. 417, pp. 394-403.

16. Burgos-Cara A., Ruiz-Agudo E., Rodriguez-Navarro C. Effectiveness of oxalic acid treatmets for the protection of marble surfaces. Materials \& Design, 5 February 2017, vol. 115, pp. 82-92.

17. Martyushev D.A. Laboratory studies of acid compositions for treating reservoir, characterized by various carbonate content and void structure of rocks. Bulletin of the Tomsk Polytechnic University. Geo Assets Engineering, 2018, vol. 329, no. 4, pp. 6-12. In Rus.

18. Lan-Anh Phan Thi, Huu-Tuan Do, Shang-Lien Lo. Enhancing decomposition rate of perfluorooctanoic acid by carbonate radical assisted sonochemical treatment. Ultrasonic Sonochemistry, September 2014, vol. 21, Iss. 5, pp. 1875-1880.

19. Tomohito Kameda, Masahito Tochinai, Toshiaki Yoshioka. Treatment of hydrochloric acid using $\mathrm{Mg}-\mathrm{Al}$ layered double hydroxide intercalated with carbonate. Journal of Industrial and Engineering Chemistry, 25 July 2016, vol. 39, pp. 21-26.

20. Dal Pozzo A., Guglielmi D., Antonioni G., Tugnoli A Sustainability analysis of dry treatment technologies for acid gas removal in waste-to-energy plants. Journal of Cleaner Production, 20 September 2017, vol. 162, pp. 1061-1074.

21. Nianyin Li, Jinxin Dai, Jianhui Li, Fengjun Bai, Zhifeng Luo. Application status and research progress of shale reservoirs acid treatment technology. Natural Gas Industry B, March 2016, vol. 3, Iss. 2, pp. 165-172.

22. Lanjun Zhang, Zenghua Li, Yongliang Yang, Yinbo Zhou, Leilei Si. Effect of acid treatment on the characteristics and structures of high-sulfur bituminous coal. Fuel, 15 November 2016 , vol. 184 , pp. 418-429.

23. Rogachev M.K., Mukhametshin V.V. Control and regulation of the process of hydrochloric acid impact on the bottomhole zone of wells according to geological and field data. Journal of Mining Institute, 2018, vol. 231, pp. 275-280. In Rus.

24. Mukhametshin V.V. On the need to create a unified and integrated method of geological and production analysis and synthesis of efficiency treatment of the bottomhole formation zone. Oil industry, 2017, no. 4, pp. 80-84. In Rus.
25. Khasanov M.M., Sitnikov A.N., Pustovskikh A.A., Roshchektaev A.P., Ismagilov N.S., Paderin G.V., Shel E.V. Scientific engineering as the basis of modeling processes in field development. Georesources, 2018, vol. 20, no. 3, pp. 142-148. In Rus.

26. Grezina O.A., Umetbaev V.G. Evaluation of the conditions for the effective use of acid-implosion effects on the bottomhole formation zone. Geology, geophysics and development of oil and gas fields, 2018, no. 2, pp. 60-66. In Rus.

27. Zeigman Yu.V., Sergeev V.V., Ayupov R.R. Klassifikatsiya fiziko-khimicheskikh metodov intensifikatsii dobychi nefti po mekhanizmu vozdeystviya na plastovuyu sistem [Classification of physico-chemical methods of intensification of oil production by the mechanism of influence on the reservoir system]. Geology, Geophysics and the development of oil and gas fields, 2017, no. 1, pp. 50-53.

28. Hyunsang Yoo, Youngmin Kim, Wonsuk Lee, Jeonghwan Lee. An experimental study on acid-rock reaction kinetics using dolomite in carbonate acidizing. Journal of Petroleum Science and Engineering, 2018, vol. 168, pp. 478-494.

29. Mohamed Mahmoud, Assad Barri, Salaheldin Elkatatny. Mixing chelating agents with seawater for acid stimulation treatment in carbonate reservoirs. Journal of Petroleum Science and Engineering, 2017, vol. 152, pp. 9-20.

30. Altunina L.K., Kuvshinov V.A., Stasieva L.A., Kuvshinov I.V. Increased oil recovery of high-viscosity oil deposits with acid compositions based on surfactants, coordinating solvents and complex compounds. Georesources, 2019, vol. 21, no. 4, pp. 103-113. In Rus.

31. Khuzin R.A., Khizhnyak G.P. Laboratory studies of the influence of the concentration and rate of acid injection on the development of wormholes in reservoir conditions. Bulletin of the Perm National Research Polytechnic University. Geology. Oil and gas and mining, 2019, vol. 19, no. 4, pp. 356-372. In Rus.

32. Shaken M.Sh. Investigation of the applicability of acid treatment in conglomerate reservoirs. SOCAR Proceedings, 2019, no. 4, pp. 23-31. In Rus.

Received: 13 March 2020.

\section{Information about the authors}

Dmitry A. Martyushev, Cand. Sc., senior lecturer, Perm National Research Polytechnic University.

Vladimir A. Novikov, 2nd category engineer, branch of OOO «LUKOIL-Engineering» «PermNIPIneft» in Perm. 